\title{
Kinetic evaluation of abiotic hydrocarbon formation in hydrothermal systems: An experimental study
}

\author{
Q. FU*, X. Chen, AND C. ONG
}

Department of Earth and Atmospheric Sciences, University of Houston, Houston, TX 77204, USA

(*correspondence: qfu5@central.uh.edu)

Hydrocarbon formation through Fischer-Tropsch type synthesis in subseafloor hydrothermal systems has been demonstrated by numerous laboratory experiments. Different than industrial application where native transition metals commonly work as the catalyst with other promoters, minerals generated during serpentinization have been used. However, the generation efficiency and corresponding reaction mechanism have yet been evaluated systematically. A series of experiments are performed with different mineral catalysts, magnetite $\left(\mathrm{Fe}_{3} \mathrm{O}_{4}\right)$ or bunsenite $(\mathrm{NiO})$, to assess the formation kinetics of hydrocarbons under geological conditions.

In each experiment, dissolved $\mathrm{CO}_{2}$ was introduced into a flow-through reactor along with $\mathrm{H}_{2}$. The potential controlling factor was adjusted individually or in combination, which included mineral catalyst, temperature, fluid flow rate, and redox conditions. Experimental results have shown that bunsenite is more effective on hydrocarbon generation than magnetite. At $150{ }^{\circ} \mathrm{C}$ with fluid flow rate in the range of 1 to $0.1 \mathrm{ml} / \mathrm{min}$, the rate of methane formation can be expressed as:

$$
R=a \frac{H_{2(a q)}{ }^{2}+b C O_{2(a q)}}{H_{2(a q)} * \mathrm{CO}_{2(a q)}}
$$

where $a=5, b=22$ for bunsenite, and $a=1, b=4$ for magnetite. The concentration of methane may increase by 2 orders of magnitude with bunsenite as the catalyst under certain conditions.

Other light alkanes $\left(\mathrm{C}_{2}\right.$ to $\left.\mathrm{C}_{4}\right)$ were also generated, but with different rates. In particular, the flow rate (i.e., residence time) of fluids may have different effects on the yield of each light alkane. It suggests that there is a tendency to reach chemical equilibrium between those light alkanes. Alternatively, the reaction pathway through organic intermediaries may change under different conditions that are rendered by variation of fluid residence time.

Further study on kinetics and intermediary identification would reveal constraints on abiotic hydrocarbon generation, and facilitate assessement of its role in organic synthesis in hydrothermal systems. 